\title{
PARASITOS MULTIRESISTENTES A DROGAS EM EQUINOS DE SÃO JOSÉ DOS PINHAIS, PARANÁ: RELATO DE CASO
}

\author{
(Multidrug resistance parasites in equines from São José dos Pinhais, Paraná: $A$ case report)
}

Julia Dall'Anese, Desire Vera Pontarolo, Úrsula Yaeko Yoshitani Thomaz de Aquino, Marcelo Beltrão Molento

Universidade Federal do Paraná, Curitiba, Paraná, Brasil.

`Correspondência: mv.dallanese@gmail.com

RESUMO: Equinos são hospedeiros de uma grande variedade de parasitos, com destaque para Parascaris spp., Anoplocephala spp., Oxyuris equi, ciatostomíneos e Strongylus spp. Os sinais de infecção variam desde leve desconforto abdominal até episódios fulminantes de cólicas, seguidas de morte. O controle destas infecções reduz estes sinais clínicos, melhorando o bem-estar dos animais. Em grande parte, estratégias de controle de parasitos preveem exclusivamente o uso de compostos antiparasitários. Os mais comuns são o fenbendazol, pamoato de pirantel, ivermectina e moxidectina, assim como as associações de bases. O uso de antiparasitários de forma supressiva, utilizando intervalos curtos (entre 30 e 45 dias) propicia a seleção de parasitos resistentes (Molento et al., 2008), inviabilizando o controle das infecções, além de manter o risco de mortalidade dos animais. A resistência parasitária depende da existência de um ou mais genes específicos na população parasitária e da pressão de seleção exercida pelo uso de medicamentos (Molento et al., 2008). Neste estudo relata-se a identificação de resistência parasitária ao febendazole (FBZ) e à associação entre albendazole e triclorfon (ABZ+TCF) identificada por meio de exame coproparasitológico (contagem de ovos por grama de fezes - OPG) seguido de teste de redução na contagem de ovos fecais (TRCOF). Amostras de fezes foram coletadas diretamente da ampola retal de seis cavalos, 14 dias antes e após a administração dos princípios. Os indivíduos estavam alojados na mesma propriedade e foram submetidos ao mesmo manejo alimentar e sanitário. Os animais receberam tratamento com alta rotação de princípios ativos, em intervalos de 8.5, 6 e 7.5 meses independentemente do OPG. Dez meses após este último tratamento, a média na contagem de OPG para o tratamento com FBZ antes e depois da administração de vermífugo foi 1792 e 900, respectivamente, com eficácia de 50\%. O tratamento com ABZ+TCF apresentou contagem média de 1555 antes e 1130 depois, com eficácia de $27 \%$. Os achados indicam que existe uma baixa eficácia para ambos os compostos, incluindo o produto com uso de duas bases químicas. Considerando-se o exposto, sugere-se a adoção de estratégias de controle que englobem a avaliação de OPG e uso de medicação somente em potros e adultos que apresentem contagem superior a 200 e 500, respectivamente. É importante verificar a eficácia dos produtos anualmente por meio do TRCOF. Outras atitudes podem envolver a quarentena de animais recémchegados, tratamento estratégico com ivermectina e controle sobre o reaparecimento de ovos por meio de OPG 28 dias após a administração do vermífugo (Coles et al., 2006 e Molento et al., 2008). O tratamento preventivo, com tratamentos a cada quatro a nove semanas; estratégico, com tratamentos regulares em algumas épocas do ano, ou quando existe aumento do número de parasitos; curativo, com tratamentos quando o animal apresenta sinais clínicos e seletivo, quando existe o monitoramento com a OPG e sinais clínicos, podem ser utilizados. Essas medidas têm por objetivo o controle do desenvolvimento do fenômeno da resistência para que animais, médicos veterinários e proprietários mantenham alternativas eficazes para adequado controle de parasitas gastrintestinais em equinos.

Palavras-chave: benzimidazóis; cavalos; multiresistência; resistência antiparasitária

\section{Referências}

COLES, G. C.; JACKSON, F.; POMROY, W. E.; PRICHARD, R. K.; VON SAMSON-HIMMELSTJERNA, G.; SILVESTRE, A.; TAYLOR, M. A.; VERCRUYSSE, J. The detection of anthelmintic resistance in nematodes of veterinary importance. Veterinary Parasitology, v. 136, p. 167-185, 2006.

MOLENTO, M. B.; ANTUNES, J.; BENTES, R. N.; COLES, G. C. Anthelmintic resistant nematodes in Brazilian horses. Veterinary Record, v. 162, n. 12, p. 384-385, 2008. 